\title{
La política de las formas
}

\author{
Manuel Vicuña ${ }^{*}$ )
}

In order to gain and to hold the esteem of men it is not sufficient to merely possess wealth or power. The wealth or power must be put in evidence, for esteem is awarded only on evidence.

T. Veblen, The Theory of the Leisure Class (1899).

En este ensayo se aborda el tránsito, en el ámbito de la historia sociocultural de la élite tradicional chilena, desde una práctica de la distinción social como puesta en escena de la diferencia a otra caracterizada por un repliegue simbólico, en que la ostentación de la propia condición privilegiada cede el paso a una disposición e incluso a una ética pública más proclive a la austeridad y la circunspección como fuente de valor cívico y rédito electoral. Se argumenta que este cambio respondió en parte a los desafíos de un sistema de partidos en vías de masificación, crecientemente competitivo y con colectividades de izquierda en alza, donde los liderazgos políticos deben apelar a formas de validación pública más democráticas. Adicionalmente, se sugiere que este ajuste de los modos de auto-presentación de la élite tradicional tenía en vista la necesidad de revertir su deslegitimación como clase dirigente, reformulando los aspectos de su identidad más cuestionados por el discurso anti-oligárquico adoptado por los sectores medios y populares. Para rastrear este proceso, se combinan dos tipos de pesquisa documental. Por un lado, se recurre al testimonio de cronistas, ensayistas y memorialistas que intentaron procesar las transformaciones asociadas con el fin del régimen oligárquico y la emergencia de una política de masas. Por el otro, se atiende al discurso crítico del lujo como factor de "descomposición social" y menoscabo del igualitarismo del ordenamiento republicano, así como foco de elaboración polémica de las éticas modernas del consumo.

$\left({ }^{*}\right)$ Decano de la Facultad de Ciencias Sociales e Historia, Universidad Diego Portales. Autor, entre otros libros, de Un juez en los infiernos. Benjamín Vicuña Mackenna, Ediciones Universidad Diego Portales, Santiago, 2009. Este artículo proviene de una ponencia presentada en el $54^{\circ}$ Congreso de Americanistas, celebrado el 2012 en Viena. Mis agradecimientos a los participantes del Simposio sobre "Elites en América Latina" por sus comentarios.

Correo electrónico: manuel.vicuna@udp.cl 


\section{El arte de apequenarse}

Para comenzar, quisiera recurrir al cronista Joaquín Edwards Bello, el testigo más lúcido y constante de las transformaciones y de las continuidades de la sociedad chilena del siglo XX. Edwards Bello escribió crónicas en forma periódica, semana a semana, durante más de cincuenta años, conformando un archivo de la cultura a la vez docta y popular, de élite y de masas, que guarda indicios muy valiosos para el análisis preliminar de los temas más disímiles. Entre éstos, destaca el material referente a los cambios en la puesta en escena de la propia condición social, sobre todo respecto de los sectores dominantes de los cuales provenía. Las virtudes y los vicios, los desplantes y las taras de la élite tradicional ocupan, en efecto, parte importante de sus reflexiones.

El 17 de mayo de 1933, Edwards Bello publicó una crónica titulada "Apequenarse, industria nacional". Ahí cuenta un episodio revelador ocurrido alrededor de 1930, en la casa de un prohombre del liberalismo. Mientras conversaban gratamente junto a la chimenea de su gabinete, un sirviente le anuncia al dueño de casa la visita intempestiva de algunos correligionarios políticos sin credenciales aristocráticas. El anfitrión, visiblemente turbado, arrojó su puro a medio fumar al fuego, se quitó su "rico gabán inglés", desarregló su ropa demasiado pulcra y partió a recibir a las inoportunas visitas en una sala contigua, "helada como ventisquero". Después de despacharlos, el político le habría comentado a Edwards Bello: "En Chile es preciso conocer el arte de apequenarse, ¿me entiende? Si yo recibiera a mis modestos correligionarios en este gabinete, fumando este habano y envuelto en este gabán, es posible que no llegaran al primer rellano de la escalera sin echar sapos y culebras contra mi persona... Si quiere usted ser político, diga en sus discursos que nació en un rancho, que su padre era gañán, su madre lavaba y fue a la escuela descalzo... Hacerse el poquita cosa es la mayor industria nacional"1.

Con esta expresión, "apequenarse", Edwards Bello señala una sutil transformación en los hábitos citadinos de los sectores más pudientes, transformación inducida, en parte, por las modificaciones en curso del escenario político como resultado del tránsito desde un sistema oligárquico, que se desfonda en la década de 1920, a otro donde empieza a perfilarse un sistema de partidos competitivo, con robustas colectividades de izquierda, y una diversificación y un recambio de las élites estatales en provecho de la ascendente clase media. En este contexto, y a diferencia de lo habitual en la oligarquía durante el siglo XIX y los comienzos del XX, cobra fuerza la costumbre de minimizar los atributos de clase, en vez de exhibirlos con desparpajo.

En 1934, al mismo tiempo que lamenta el declive del patricio a la antigua, es decir del prohombre capaz de mostrar aplomo en toda circunstancia y un orgullo de clase sin afectación, Edwards Bello diagnóstica la condición presente del oligarca: "El hombre actual teme demasiado a la mordacidad de las turbas. Sabe que ellas dominan al cabo, y no se atreve a desafiarlas con los ocho reflejos del sombrero diferenciador" ${ }^{\prime 2}$. Usar un frac o un sombrero tongo, fumar un habano o frecuentar el selecto Hotel

\footnotetext{
${ }^{1}$ Joaquín Edwards Bello, Crónicas reunidas (III) 1931-1933, Ediciones Universidad Diego Portales, Santiago, 2011 , pp. 157-158.
} 2 Joaquín Edwards Bello, Crónicas reunidas (IV) 1934-1935, Ediciones Universidad Diego Portales, Santiago, 2012 , p. 229. 
Crillón, parecen una osadía suicida, señala en otras crónicas, para cualquier líder con aspiraciones políticas serias. Edwards Bello atribuye esto a la crisis de la deferencia o del "sentido de la jerarquía" como un valor medular de la sociedad tradicional, y al consiguiente destape del resentimiento y del odio de clase como virulentos sentimientos cotidianos (todo lo cual provocó reflexiones apesadumbradas por parte de diversos miembros de la oligarquía).

Edwards Bello tematizó este fenómeno en distintas crónicas de los años veinte y treinta; registró e indagó en caliente, sobre la marcha, los procesos conexos de la democratización de la sociedad chilena y de la crisis de los tradicionales "modos de ser aristocrático"(al menos en público) ${ }^{3}$. La irrupción política de la clase media y de los sectores populares en la escena nacional llevó a una reformulación de las reglas de convivencia o las formas de relacionarse entre los individuos de las distintas clases sociales. La ostentación, antes impune, de pronto motivaba el repudio; ahora resultaba preferible disimular las marcas de clase.

Este arte de apequenarse, un arte del disimulo y del camuflaje, que Edwards Bello satiriza como una maniobra táctica y una impostura de los políticos de clase alta decididos a mantenerse activos en el mundo de la política democrática de masas, también cundió entre las mujeres y, generalmente, entre quienes, por una u otra razón, se veían expuestos a un medio social heterogéneo. Detectado por primera vez en los años 30, el arte de apequenarse se mantuvo vigente por décadas, si bien la expresión de Edwards Bello no logró imponerse. Una de las entrevistadas por María RosariaStabili para su libro de historia oral sobre el "sentimiento aristocrático" en Chile, concluye:

"Mirando hacia atrás y pensando en mi época de estudiante en la universidad (años sesenta), me doy cuenta que quienes sentían no pertenecer a los grupos percibidos como de elite, le suponían a esas personas un poder y privilegios bastante irreales. La distancia era percibida como enorme, había mucha rabia. Y esto daba origen a feroces agresiones. Así que era mejor para la convivencia, o mejor dicho para la sobrevivencia, especialmente en el caso de la gente rica, más bien ocultar que ostentar" ${ }^{\prime \prime}$.

Durante el siglo XX, sobre todo tras la gran crisis de 1929, hay indicios, entonces, que aluden a un cambio significativo en la puesta en escena de la distinción social por parte de la "aristocracia" chilena. Tal como enseña la sociología de las élites, de Veblen a Bourdieu, todo grupo dominante debe exhibir "signos de superioridad" capaces de refrendar, ante los otros, su eminente posición social. Esto puede ocurrir apelando a recursos externos, como el consumo conspicuo, o mediante el despliegue de atributos morales o estéticos dignificantes ${ }^{5}$. En otras palabras, así como se puede ostentar el lujo, también se puede ostentar la austeridad, haciendo de ésta una expresión visible

\footnotetext{
${ }^{3}$ Sobre este asunto, sigue siendo de interés el libro de Luisa Barros Lezaeta y Ximena Vergara Johnson, El modo de ser aristocrático: el caso de la oligarquía chilena hacia 1900, Editorial Aconcagua, Santiago, 1978.

${ }^{4}$ María RosariaStabili, El sentimiento aristocrático. Elites chilenas frente al espejo (1860-1960), Editorial Andrés Bello y Centro de Investigaciones Barros Arana, Santiago, 2003, p. 74.

${ }^{5}$ Para una excelente revisión de la literatura sociológica asociada al tema, véase Jean-Pascal Daloz, The Sociology of Elite

Distinction: From Theoretical to Comparative Perspectives, PalgraveMacmillan, New York, 2010; y, del mismo autor,

"Elite Distinction: Grand Theory and Comparative Perspectives", Comparative Sociology, Vol.6, 2007, pp. 27-74.
} 
de la distinción social. La primera alternativa, la del lujo ostentoso, predominó en el Chile tradicional. Contra este telón de fondo, originalmente desplegado durante la segunda mitad del siglo XIX, se irá perfilando la figura del arte de apequenarse, propia del siglo XX.

La historia es conocida, de modo que evitaré extenderme. Conforme avanzaba el siglo XIX, la élite se empeñó en remedar a la alta burguesía europea. La riqueza minera y agrícola, impulsada por los flujos del comercio, solventó un gasto dispendioso. Y éste se tradujo en la construcción de mansiones señoriales, en largas estadías en Europa y un consumo de bienes suntuarios (carruajes, vestidos, mobiliario, joyas) que distintos autores, nacionales y extranjeros de varias naciones, calificaron como compulsivo, desmesurado o exorbitante. El entorno material de la capital cambió radicalmente, incluso antes de que el salitre arrebatado a Perú y Bolivia engrosara los caudales de la riqueza pública y privada. Santiago nunca se transformó en el "París de América", tal como soñaba el intendente Benjamín Vicuña Mackenna en la década de 1870, pero aun así sus barrios prósperos, con sus mansiones señoriales, sus parques de ocio aristocrático y sus paseos elegantes, lograron evocar, para nativos y visitantes, las pompas de las grandes ciudades europeas ${ }^{6}$. Los años en torno al 1900 marcaron la culminación de esa opulencia desplegaba a vista y paciencia de todo el mundo, con una desinhibición teatral y un exhibicionismo plutocrático que representan la antítesis del arte del disimulo documentado por Edwards Bello.

\section{El lujo como patología social}

Ahora bien, habría que preguntarse si esta tendencia proclive al recato respondió solo a una retirada estratégica motivada por los cambios del entorno social. En lo que sigue quiero sugerir que este vuelco también fue impulsado por una tradición crítica del lujo con antecedentes desde la década de 1830. Esta tradición remite a una ética del consumo y una expectativa republicana sobre los atributos morales de una clase dirigente y una sociedad fundada, normativamente, en torno al idea político del ciudadano como sujeto autónomo. Esta crítica corre a la par del auge del lujo como fenómeno social, y comprende a algunos de los pensadores más prominentes del siglo XIX y de comienzos del XX, en Chile al menos.

En 1839, en las páginas del periódico oficialista El Araucano, su redactor, Andrés Bello, estrenó la reflexión sobre el lujo como algo de alcance público, intentando validar una posición intermedia o conciliatoria entre dos posturas extremas, una anclada en la moral, otra en la economía7. Por un lado, Bello discierne el discurso de los "moralistas" que ambicionan "proscribir el lujo", en razón de los males que acarrearía; por el otro, identifica a los "economistas" que lo estiman valioso a todo trance. Como moderador de unas tradiciones intelectuales en pugna, Bello se propone depurar ambas visiones hasta alcanzar una síntesis que supere tanto la condena a ultranza como la exaltación irreflexiva. Busca un "término medio, en que el interés de la producción se equilibre

\footnotetext{
${ }^{6}$ He desarrollado extensamente estas transformaciones socio-culturales y urbanísticas en La belle époque chilena. Alta sociedad y mujeres de élite, $2^{a}$. ed., Editorial Catalonia, Santiago, 2010.

${ }^{7}$ Obras completas de don Andrés Bello, vol. VII: Opúsculos literarios i críticos II, Impreso por Pedro G. Ramírez, Santiago, 1884, pp. 433-41.
} 
con los goces del consumo"; un equilibrio inestable, más pragmático y contingente que rígidamente normativo, pues lo superfluo de hoy puede convertirse, mañana, en algo necesario, y la definición de lo lujoso y de la racionalidad o irracionalidad del gasto se precisan a la luz de la capacidad adquisitiva de cada consumidor: el lujo del trabajador no coincide con el lujo del potentado.

Contra los "filósofos de la escuela ascética", idólatras de la frugalidad, argumenta a favor del desarrollo de la industria de los productos suntuarios, invocando la generación de empleos calificados, el uso de capitales de otro modo ociosos, y el gradual despliegue de manufacturas más sofisticadas. Para Bello, heredero en esto de ideales dieciochescos, el lujo es un índice y agente de la civilización que dulcifica las costumbres y refina la vida citadina. El lujo, motor de la economía y de la sociedad, en síntesis. Prohibir el lujo, por tanto, supone inhibir el desarrollo de mercados, el crecimiento de la población y la circulación de la riqueza favorable a la "clase trabajadora" empleada en producir los bienes suntuarios. Hay que ser a la vez indulgentes y vigilantes frente al lujo, sobre todo si estimula las industrias locales y, así, mejora las condiciones de vida de la "clase trabajadora". Debidamente dosificado, es un tónico; consumido en exceso, un veneno.

Bello escribe sobre el lujo cuando recién empieza a manifestarse en Chile, cuando es algo muy incipiente, también muy acotado, pero así y todo ya tiene detractores entre "ciertos políticos atrabiliarios, laudatores temporis acti", es decir, amigos del pasado. Su intervención, entonces, participa de un debate en ciernes. En defensa del lujo moderado como agente de civilización, Bello remite a Voltaire, de hecho el único autor que menciona o cita en su artículo, aprobando su defensa de lo superfluo como algo necesario para la prosperidad de las sociedades. Voltaire fue solo uno de los grandes defensores dieciochesco del lujo en virtud de su utilidad pública. Esta forma de razonamiento solía inspirarse en la lectura admirativa de Bernard de Mandeville, quien, en su iconoclasta Fable of the Bees (1714), había redimido los vicios privados como el orgullo, la envidia y la vanidad, apelando a su impacto positivo en el desarrollo de las industrias y en el bienestar social. A la zaga de Voltaire, Bello esbozó una ética del consumidor ilustrado, alguien en principio capaz de sortear los escollos del hedonismo desmesurado y el ascetismo extremo. En el fondo, la defensa del lujo moderado tal como la planteó Bello, se sitúa sobre todo en el campo de las consideraciones económicas y, en particular, en las dinámicas del capitalismo como fuerza activa en la modernización de las sociedades tradicionales.

Con el tiempo, en Chile, la reflexión sobre el lujo se fue volviendo más apegada al contexto local, menos teórica, menos general o hipotética. Y esto porque el lujo y la ostentación, al menos desde la década de 1850, adquirieron la contundencia de un fenómeno social llamativo. La prosperidad asociada al desarrollo de la minería y a las exportaciones agrícolas ya había modificado las condiciones materiales de vida de los sectores pudientes de la capital. Ya en esa época, tal como constató un testigo estadounidense, la pasión por el lujo había desbordado los márgenes de la élite, hasta alcanzar incluso a los círculos de artesanos: 
“(...) en público, les apasiona vestirse elegantemente, y un forastero difícilmente podría sospechar que el hombre que encuentra en una amplia capa de paño, escoltando a una mujer engalanada con sedas y joyas, ocupa en la escala social un rango no superior al de un hojalatero, carpintero o tendero... Llegarán a cualquier extremo con tal de obtener finos atuendos y refinados muebles (...) Esta disposición (...) domina a toda la sociedad"s.

¿Cómo explicarse esa afición aparentemente irracional al lujo, con prescindencia de los ingresos reales? El lujo o el consumo conspicuo operaron como factor de diferenciación en un periodo de recomposición de las jerarquías sociales y políticas, en el paso de una sociedad tradicional, de pasado estamental, a otra donde el peso de la herencia resultaba menos fuerte, el estatus resultaba más contingente, y el principio normativo de la igualdad erosionaba la identidad aristocrática de la clase dirigente. La exhibición citadina del lujo, a veces llevada a cabo con gran conciencia escénica, pretendía inspirar sentimientos de conformidad con su privilegiada situación social y política, que desentonaba con el nuevo horizonte de la legitimidad democrática. En el caso de los artesanos, que conformaban la crema y nata del mundo popular y, por lo mismo, un sector subordinado pero no extraño al ámbito de la ciudadanía activa, el cultivo de la apariencia, del vestir "decente" por oposición explícita a la figura degradante del "roto", simbolizó, tal como se ha argumentado en un estudio reciente, la reivindicación de su calidad de actor social digno de plenos derechos civiles y políticos". Esta dinámica de "emulación perversa" que, como afirmó un periódico de la época, alcanzaba las proporciones de una "epidemia, estaba produciendo un severo desajuste de la sociedad chilena: "Nadie quiere parecer lo que es; todos se empeñan en parecer lo que no son. La sociedad presenta un desarreglo general, merced a que todos invaden los grados superiores de la jerarquía social. (...) Nadie quiere desentonar en este coro de magnificencias" ${ }^{\prime 10}$.

La década de 1850, quisiera insistir en esto, marcó el comienzo de un debate más amplio, cuyo diagnóstico se particulariza con referencia explícita al caso chileno. Y este debate no solo se expresa formalmente a través de publicaciones como libros o artículos de periódicos; también se desenvuelve de modo informal, al calor de las conversaciones. Hay indicios de que el lujo, al menos en sectores de la élite, más que una extravagancia o una opción individual, es asumido como una forma de acatamiento a las expectativas sociales derivadas de su identidad de clase. "Muchas veces se oye vituperar a tal o cual persona", hizo constar un articulista, "de que "no hace honor a su fortuna, que no ostenta' " ${ }^{11}$

En este contexto, el año 1858 el periodista y político liberal Pedro Félix Vicuña publicó El porvenir del hombre, o la relación íntima entre la justa apreciación del trabajo y la democracia. Se trata de un libro ambicioso y, aun más, desmesurado. Plagado de referencias políticas, sociales y económicas, incursiona en la economía

\footnotetext{
${ }^{8}$ J.M. Gilliss, Lieut., The U.S. Naval Astronomical Expedition to the Southern Hemisphere, during the years 1849-50-5152, vol. I: Chile, A.O.P. Nicholson, Washington DC, 1855, p. 219.

${ }^{9}$ James A. Wood, The Society of Equality: Popular Republicanism and Democracy in Santiago de Chile, 1818-1851, University of New Mexico Press, Albuquerque, 2011, p. 127.

10 "Del abuso en los gastos de lujo", El porvenir de las familias, 20 de octubre de 1857.

11 "Sobre los gastos de lujo", El porvenir de las familias, 6 de noviembre de 1857.
} 
política para atender a los desafíos de la inminente "revolución universal" originada en las desigualdades entre capital y trabajo. La fuerza insurreccional desatada por la revolución francesa de 1848 habría significado un preámbulo de ese cataclismo histórico. Vicuña confiaba en que el crédito público, la redistribución de la tierra y el proteccionismo económico disiparan las tensiones sociales, además de restituirle al trabajo su valor como única fuente de riqueza, en desmedro de un capital devenido despótico por la usura y el uso de la propiedad como inductor del pauperismo.

Vicuña es un liberal de la vieja guardia, de los pipiolos de la década de 1820, de esos afiliados al repertorio de valores del republicanismo y a su idea de la libertad como no dominación arbitraria de una comunidad de ciudadanos. Hostigado y desterrado por los gobiernos autoritarios posteriores a 1830, ambiciona derechos e instituciones no solo formales; elecciones libres; una opinión pública inquisitiva e dependiente; y que la "propiedad y la riqueza no sean poder social ni político, estableciendo de hecho el principio de la igualdad, dando siempre la preferencia al mérito y la virtud".

El interés de su libro con relación al lujo radica en su diagnóstico sobre el consumo conspicuo como una patología afincada en la sociedad chilena, una patología que turba la organización política en perjuicio del arreglo democrático que juzga acorde al orden republicano. Escribe:

"El lujo es una pasión que se desarrolla entre nosotros no en relación con nuestras ganancias, ni de la renta constante de la propiedad. La idea de aparecer ricos, desde que la riqueza es un poder político, ha invadido a todas las clases; la ostentación de la riqueza es entonces un impulso aristocrático que nuestra sociedad ha recibido de la organización política establecida entre nosotros. El goce, el placer y satisfacción que el dinero puede inspirar a un hombre verdaderamente rico no se halla entre nosotros, desde que se carece de todo lo confortable de la opulencia, y se trabaja en la ostentación de lo que sólo pueda deslumbrarlos ojos ajenos. Nuestro lujo consiste en la ropa, en muebles y coches. En el pueblo más industrial en esta clase de productos Chile ha alcanzado un renombre por su riqueza; en París los grandes fabricantes de carruajes, los más afamados ebanistas, los sastres, modistas, etc., todos los que tiene el comercio del lujo nos conocen por un pueblo muy rico"12.

Aquí ya aparece un elemento central de la crítica del lujo predominante a futuro: la idea de la ostentación como un mecanismo irracional de distinción social que corrompe las costumbres, arruina a las familias y, al final, hace del espectáculo de la riqueza, no rara vez fingida, una forma de atribución de valor social indiferente al mérito y a la virtud cívica.

La crítica del lujo se volverá más acuciante en la década de 1870, cuyos primeros años se caracterizaron por un boom económico asociado al descubrimiento de la mina de plata de Caracoles. Entonces la censura al lujo se radicaliza, se agrava el diagnóstico sobre su virulencia en la sociedad chilena, y la dimensión de género adquiere contundencia como categoría crítica.

\footnotetext{
${ }^{12}$ Pedro Félix Vicuña, El porvenir del hombre o relación íntima entre la justa apreciación del trabajo y la democracia, $2^{\mathrm{a}}$ ed., en Biblioteca Fundamentos de la Construcción de Chile, Tomo XXXVII, Cámara Chilena de la Construcción, Pontificia Universidad Católica de Chile, y Dirección de Bibliotecas, Archivos y Museos, Santiago, 2010, pp. 102-03.
} 
En 1873, la novelista Rosario Orrego publicó el artículo "El lujo y la moda", texto pionero en la feminización del consumo conspicuo ${ }^{13}$. El tono de alarma se ha vuelto estridente, dada la seriedad del diagnóstico. Orrego arranca definiendo al lujo como una "moderna plaga" que amenaza a la sociedad chilena con la inminente disolución de sus "vínculos más sagrados". Aduce en su favor el refrendo empírico de las apreciaciones de primera mano -la verdad del testigo directo- como fuente de autoridad de su crítica social. ¿Qué advierte esta observadora de "religiosa imparcialidad"? Un apego febril al lujo como pasión por la distinción social, como una pulsión irracional que afecta, antes que nada, a las mujeres:

“Nos duele confesarlo, pero la verdad es que las mujeres (salvo honrosas excepciones) son las grandes sacerdotisas del abominable culto tributado al becerro de oro. Ellas son las que para satisfacer su sed de lujo impelen a sus maridos y hacen comprender a sus novios la necesidad de ganar mucho dinero. Si los hombres hacen las leyes, las mujeres hacen las costumbres: sobre ellas cae la mayor responsabilidad de todo lo que tiene de materialista, de interesado y de penoso para toda alma noble las costumbres del siglo".

De este hecho se desprenden, a su turno, una serie de consecuencias muy nocivas para la sociedad y las familias: ruinas por despilfarro, "quiebras fraudulentas, expatriaciones forzosas, incendios misteriosos" y una mayor resistencia masculina a contraer matrimonio, dados los costos asociados. La feminización del consumo se convertirá, a futuro, en una encrucijada del pensamiento social afecto al ideal de la domesticidad, es decir, a la definición normativa de la mujer como una madre y esposa cuya misión es velar por el bienestar espiritual y material de su familia, convirtiendo al hogar en refugio psíquico y afectivo ante las convulsivas experiencias de la vida urbana y del trabajo moderno.

Sólo un año más tarde, en 1874, el entonces diputado Marcial González, autor de un celebrado libro de economía política, dicta la conferencia "Nuestro enemigo el lujo", en la Academia de Bellas Letras de Santiago ${ }^{14}$.

Siconsideramos el texto de Bellocomo punto de partida dela discusión sobre ellujo, el camino recorrido, o mejor, el desplazamiento de los términos del debate, resulta significativo. Bello trata el asunto cuando el lujo dista de ser un fenómeno caracterizado como un gravísimo padecimiento de la sociedad; discute a partir de la identificación, grosso modo, de dos escuelas antagónicas sobre el lujo, pero esa discusión nunca alza la voz, siempre mantiene la serenidad de un juicio optimista y poco apremiante. Con González, en cambio, impera el pesimismo. Éste se funda en una amalgama de consideraciones eruditas en diálogo con autores pertinentes al tema (como Say, Montesquieu, Voltaire, Hume o Bacon); y, por otra parte, en observaciones del entorno y estadísticas de importación de bienes suntuarios. Si Orrego se situaba en el lugar de enunciación del testigo privilegiado, González adopta la posición del vocero de la razón avalado por la ciencia.

Para González, el lujo moderno es "el gasto excesivo y de pura ostentación". A la desmesura, suma la exhibición social, dimensión simbólica vinculada al escenario citadino. Montesquieu

\footnotetext{
${ }^{13}$ Rosario Orrego, Sus mejores poemas, artículos y novela corta “Teresa", Nascimento, Santiago, 1931 , pp. $62-67$.

${ }^{14}$ Marcial González, Estudios económicos, Imprenta Gutenberg, Santiago, 1889, pp. 429-61.
} 
había asociado el hambre de distinción satisfecha con el lujo al anonimato de las ciudades, como compensación al efecto anonadador de las masas. González opta por otra hipótesis: el lujo como patología del desarrollo democrático, dado el deseo de contrarrestar el "espíritu de igualdad" mediante la distinción a través del consumo. Escribe:

\begin{abstract}
"Mas, sea lo que fuere del sentido de la palabra (lujo), el hecho es, señores, que basta abrir los ojos para conocer que el espíritu de igualdad, base fundamental de la sociedad moderna, crea y desarrolla cada día más en los individuos y en los pueblos cierta vanidosa emulación por aparentar y hacer figura; un grande amor por las satisfacciones materiales y un deseo ardiente de distinguirse, no tanto por obras grandes y buenas como por la ostentación de cosas caras, a veces de poca o ninguna utilidad y a veces de pura fantasía, pero que dan al vulgo una alta idea de la riqueza, cultura y generosidad de los que poseen. Este hecho, que es como la resultante de nuestro modo de ser actual, explica por sí solo nuestra marcada afición al lujo. El mal crece con los adelantos democráticos y así puede llegar a ser una calamidad, porque convierte los vicios privados en vicios públicos y porque fomenta las bajas pasiones hasta merecer los anatemas del legislador y del filósofo. Pero no por eso deja de ser uno de los elementos constitutivos de nuestra vida de hoy, plausible o vituperable, según los casos; que puede extenderse por la pasión o modificarse por las costumbres, que, como hecho sociológico fatal, es indispensable tomarlo en cuenta por su influjo en la marcha de un país nuevo y de civilización incipiente como el nuestro".
\end{abstract}

Pensando en la sociedad chilena, González llega a calificar al lujo intemperante como una "lepra social" en estado avanzado, y esta enfermedad, que describe con la atención de un patólogo, representa, a su juicio, un síntoma de la "decadencia" del país. Esta decadencia excede la dimensión económica, si bien él no pasa por alto los efectos perniciosos del lujo incontinente en la sana administración de las rentas, en la descapitalización de la estructura productiva y en la dependencia de manufacturas externas. Toda su reflexión está saturada de consideraciones sobre la moral pública y privada, a partir de lo cual emerge un discurso crítico sobre el destino del proyecto nacional. El lujo como impostura de la opulencia esconde el espectro del deterioro económico, político y moral de la nación. La descripción del país que hace González remite, por oposición, al ideal de la república como una comunidad de ciudadanos, de sujetos capaces de anteponer el bien común al interés personal. Casi haciendo el luto de un Chile extinto, del Chile más virtuoso del pasado, González señala:

“(...) el ahínco de los goces y lo ilimitado del orgullo son los distintivos de esta época. Por eso los que observan nuestra sociedad se sorprenden de la baja que, respecto de los tiempos pasados, se nota en el nivel de las ideas y hasta de los sentimientos generales (...) la clase opulenta no quiere sino gozar por todos los medios y tratar de aumentar su riqueza a toda costa. La juventud misma hace alarde de una vocación precoz por el gusto caro y los placeres fáciles. Siento decirlo, pero el deseo de estar lo mejor posible y en todas las circunstancias posibles es para muchos el único estudio y el pensamiento constante de su vida. Nadie se interesa ya por la política, ni el amor al bien público: la patria, las glorias del arte y hasta la dulce sociabilidad, parecen adormecidas. Faltan evidentemente estímulos que den impulso al desarrollo intelectual y moral, el corazón se muestra sordo al llamado de las nobles emociones, y la vida regalada, el agio por toda ocupación y los hábitos de ocio y de molicie continua ciertamente que no son las palancas mejores para levantar y retemplar nuestro carácter nacional". 
Este diagnóstico responsabiliza a la clase dirigente en su conjunto, puesto que la dinámica del lujo se propaga, a todo nivel, por el deseo de emulación que gatilla la "sociedad decente". "Tal vez será de la esencia de nuestra democracia chilena el cambiar la igualdad, (...) por un conato ardiente de equipararnos con los que tienen mayor fortuna que nosotros". Esta pasión mimética, en efecto:

“Es (...) una tendencia general y arraigada, un gusto fijo, una pasión que domina sobre todo entre las gentes de mediana fortuna: es algo que constituye una especie de enfermedad social y que podría llamarse "el furor de hacerse notar en el número harto crecido ya de los felices y los ricos". Y dada esta perversión del sentimiento democrático y conocida nuestra debilidad por distinguirnos o más bien por igualarnos los pobres con los acaudalados, nada más natural que el que esa lepra se extienda, porque la pasión por el lujo domina más que las otras y de ordinario arrastra aún a los que se creen cuerdos a los más locos y censurables extravíos".

Esta crítica a la élite en función de su relación viciada con el consumo constituirá un elemento importante de la crítica antioligárquica de inicios del siglo XX. Esta condena se desarrolló en diversos ámbitos de la opinión pública, y comprometió a autores de distintas clases sociales y orientaciones políticas. El diagnóstico sobre la "sed de lujo" como una epidemia de la sociedad pudiente orbitó en torno al campo semántico de la "crisis" nacional ${ }^{15}$. Los intelectuales que hacia la época del Centenario realizaron un balance crítico del estado actual del país, a menudo repararon en las falencias de la élite tradicional como clase dirigente y, de modo particular, en su responsabilidad con respecto a las promesas incumplidas del progreso.

La sensación de hallarse en medio de una "crisis moral de la República", crisis ya rotulada el año 1900 por el político radical Enrique Mac-Iver, se advierte en el trasfondo de los autores que, de hecho, luego serían conocidos como los "testigos de la crisis"16. Si bien los diagnósticos varían entre unos y otros, suelen coincidir en su vocación crítica al estilo de vida disipado de la alta sociedad. Por ejemplo, en Nuestra inferioridad económica (1911), uno de los libros más emblemáticos del nacionalismo en vías de articulación intelectual, el historiador Francisco Antonio Encina evalúa los impedimentos a la capitalización y al desarrollo de la industria, la minería y el comercio. Para Encina, estos impedimentos en parte se derivan de los "consumos de lujo, de la inveterada tendencia a la ostentación". Como ésta se satisface con bienes suntuarios de origen extranjero, el consumo conspicuo sería una fuerza nociva para la producción local, que así cede posiciones económicas a las importaciones y a los inmigrantes. Otro de los pensadores nacionalistas de la época, el profesor Tancredo Pinochet LeBrun, publicó en 1909 un libro titulado, reveladoramente, La conquista de Chile en el siglo XX, en cuyas páginas se critica a "nuestros elegantes", o a la sociedad pudiente, en tanto máxima encarnación del "desprecio por lo nacional", desprecio materializado en sus patrones de consumo, los cuales documenta con el rigor por el detalle de un inventario inculpatorio.

\footnotetext{
${ }^{15}$ Véase, por ejemplo, Julio Zegers, Estudios económicos 1907-1908, Imprenta Nacional, Santiago, 1908 , p. 8.

${ }^{16}$ Para una antología de esos textos críticos, consúltese Cristián Gazmuri, (ed.), El Chile del centenario, los ensayistas de la crisis, Instituto de Historia de la PUC, Santiago.
} 
La historia del capitalismo, en sus fases más tempranas, ha sido tradicionalmente narrada a partir del desarrollo de una serie de fenómenos inscritos en la esfera de la producción. Sólo recientemente la historiografía y las ciencias sociales han consagrado a la historia del consumo como un factor imprescindible para dar cuenta de la génesis y del desarrollo del capitalismo. La "sociedad de consumo", si antes identificada con pleno siglo XX, ahora también ha empezado a caracterizar etapas previas de la historia, y no como resultado de la revolución industrial sino como agente propiciador suyo, como fuerza propulsora por derecho propio. En general, la "sociedad de consumo" precedió a la producción masiva y esta sola constatación, motor del "giro anti-productivista" de la historia social, económica y cultural del capitalismo, ha situado a la demanda (y no ya a la producción) en el centro de la correspondiente atención académica ${ }^{17}$.

En este marco de referencia, el consumo como práctica social ha sido analizado y evaluado a partir de las dicotomías entre racionalidad e irracionalidad, y libertad y opresión (o, más bien, caducidad de la autonomía personal). Todos los autores aquí abordados rondan estas dicotomías clásicas. El lujo como pasión desbocada, ¿no es una muestra de irracionalidad? El lujo como pasión mimética aspiracional, ¿no implica una forma de esclavitud? En definitiva, en el caso chileno las éticas del consumo representan una dimensión del pensamiento no sólo económico sino también social y político, que acompaña, como una apostilla crítica, los procesos de modernización de la sociedad y la historia de sus relaciones de poder. En virtud de las éticas del consumo, se ejerció la crítica social y se aportaron elementos para la devaluación del prestigio y la hegemonía de la élite tradicional. El arte de apequenarse parece haber provenido de las presiones del medio político post régimen oligárquico, tanto como de una censura derivada de unas prácticas públicas de consumo plutocrático.

Aquí he ofrecido un esbozo preliminar del asunto, pistas más o menos conexas de la crítica al lujo, algo que sería interesante profundizar situándola debidamente en las matrices intelectuales que la apuntalaron. Es sabido que el clero católico viene criticando el lujo desde hace siglos, como resultado de la vieja doctrina del contemptus mundi. Por cierto Chile no ha sido una excepción a esa regla. En este ensayo, sin embargo, me he atenido a las vertientes seculares del tema.

Durante el siglo XIX, en efecto, la crítica radical al lujo remite a ciertas vertientes del pensamiento republicano y a su noción del lujo (basta pensar en Rousseau y en su idealización de la vida rústica) como una pasión mundana dañina para el carácter independiente del ciudadano, toda vez que lo somete a la esclavitud de unas necesidades superfluas. Esta forma de esclavitud también podía asociarse al vínculo de dependencia del adicto al lujo respecto de los prestamistas, algo sobre lo cual Pedro Félix Vicuña no fue el único en reparar, ya en la década de 1850.

Iniciado el XX, la crítica al lujo tiende a alojarse en un marco de referencia nacionalista; a diferencia del pasado, ahora se esgrime el anti-patriotismo del consumidor aficionado a las mercancías extranjeras e inapetentes ante los productos sin aura de la industria chilena, como uno de los factores detrás del insatisfactorio progreso nacional.

${ }^{17}$ Roberta Sassatelli, Consumer Culture: History, Theory and Politics, Los Angeles, London, New Delhi and Singapore: SAGE Publications. 